\title{
Understanding the impact of removing a fence between two game ranches with different management objectives
}

\author{
Mohammed E. Alrashidi and John W. Hearne and Lynne McArthur \\ School of Mathematical and Geospatial Sciences, RMIT University, Melbourne \\ Email: s3441802@student.rmit.edu.au
}

\begin{abstract}
When two adjacent properties have opposing management strategies for the same resource, problems arise regarding equitable benefits. This raises questions relating to the equitable distribution of economic benefits of such resources. The issues relate to the conflicting management objectives of these resources such as consumption versus non-consumption. In this study, we consider these problems in the context of potential commercial harvesting and environmental conservation of African wildlife.
\end{abstract}

To obtain a better understanding of the implications of these problems, we investigated a scenario where two neighbouring properties were engaged in a co-operative and non-coopertive enterprise respectively. This paper describes modeling the movement of animals in an African environment on neighbouring properties with and without a common fence, which implies cooperative and non-cooperative regimes. This analysis was based on the assumption that the species distribute themselves according to the Ideal Free Distribution (IFD).

We found that when the fence is removed, the returns from the non-consumptive tourism enterprise is decreased due to the animal migration to the neighbouring property, which has a lower density of animals because of removal from hunting. Ths model provided insight into the effect of migration on the profits for both landowners.

Using a model to explore these factors we find that there is an optimal solution to the problem of the equitable distribution of returns for both landowners.

Keywords: Resource modeling, conservancy, merging game ranches, wildlife tourism, wildlife harvesting 
Mohammed et al., Understanding the impact of removing a fence between two game ranches with different management objectives

\section{INTRODUCTION}

Combined nature reserves are quite frequently seen in South Africa and Namibia (Nogueira and NogueiraFilho, 2011, Lindsey et al., 2013). Basically, a collaborative nature reserve is a location in which nearby landowners have collectively pooled their resources to form large units where wildlife can roam freely within that unit (Leimgruber et al., 2001, Lindsey et al., 2007, Mwakiwa et al., 2013). Individual ownership of those reserves still exists, but management of each unit is done as a single entity. A number of private land users are able to provide wildlife-viewing safaris on private territories due to the increasing demand for viewing the wildlife in Southern Africa and due to the high earnings of providing such a facility (Prins et al., 2000, Lindsey, 2011, Child et al., 2012). In comparison to other developing regions, this region has a comparative advantage with regard to its diverse endemic wildlife species and high number of wildlife populations. Selling of live game, subsistence hunting for meat, culling/cropping, and safari hunting are some known types of consumptive wildlife use (Child, 2009). Regional and international trading of products such as meat and skins is also carried out (Behr and Groenewald, 1990, Roth and Merz, 1997).

To this end, despite the advantages there is a reluctance to combine nearby resources when landowners have different objectives for utilizing their resources. This raises questions relating to the equitable distribution of harvest of such resources. That can also raise issues relating to the management of these resources as utilisation objectives might be in conflict (e.g. consumptive vs. non- consumptive). The problem to be addressed is that the apprehensions among ranchers about losing their wildlife through migration to the adjacent landowners is one constraint towards establishment of combined conservancies for landholders. Therefore, it is important to investigate equitable distribution of returns for landholders of the adjacent ranchers to these mobile resources. This would be possible through successful models for collaborative management of wildlife. The need for any physical restrictions between neighbouring wildlife ranches is eliminated if such agreements are formed.

A fundamental tool for studying the dynamics of a population system is the use of differential models, which have been used successfully for many years in biological systems and population modeling (Clark, 2010, Taubes, 2001). The models we use have logistic growth and harvesting components for the species on the two adjoin properties. Also included in this model are migration components on both properties.

In this paper, we investigate the equitable distribution of returns for two different landowners with two different management objectives utilising resources roaming between their neighbouring properties. We model the neighbouring properties with and without the common fence. To this end, this enables us to understand the consequences of resources roaming freely between the two properties.

\section{FORMULATION}

Differential equations were used in this study to model the species population where the harvesting rate affects their stable population numbers. To this end we focus on a situation where two neighbouring properties in a cooperative enterprise have conflicting management objectives (e.g. consumptive and non-consumptive). The migration is modeled under the ideal free distribution, which is governed by the ratio of animals' density to carrying capacity. The animal populations are assumed to freely cross borders between properties. The movement of animals to and from the property, the migration, under the IFD would take the form (E. J. MilnerGulland, 2011, Fretwell and Lucas, 1970):

$$
\begin{aligned}
& \because \frac{P-\alpha \text { Migration }}{K}=\frac{P_{\text {Next property }}+\alpha \text { Migration }}{K_{\text {Next property }}} . \\
& \therefore \text { Migration }=\alpha \frac{K_{\text {Next property }} P-K P_{\text {Next property }}}{K+K_{\text {Next property }}} .
\end{aligned}
$$

where, $K$ is carrying capacity, $P$ is the animal population and $\alpha$ is the migration coefficient representing the rate. Thus, the animal movement under the IFD between two properties takes the form:

$$
\operatorname{Migration}_{i}\left(P_{i}, P_{j}\right)=\alpha \frac{K_{i} P_{j}-K_{j} P_{i}}{K_{i}+K_{j}} \quad, i \neq j \text { for } i=1,2
$$

We assumed two identical properties for this analysis with common borders. However, the population models for property 1 and property 2 respectively is presented by the following system differential equations: 
Mohammed et al., Understanding the impact of removing a fence between two game ranches with different management objectives

$$
\begin{aligned}
& \frac{d P_{1}}{d t}=r P_{1}\left(1-\frac{P_{1}}{K_{1}}\right)-\alpha\left(\frac{K_{2} P_{1}-K_{1} P_{2}}{K_{1}+K_{2}}\right) \\
& \frac{d P_{2}}{d t}=r P_{2}\left(1-\frac{P_{2}}{K_{2}}\right)+\alpha\left(\frac{K_{2} P_{1}-K_{1} P_{2}}{K_{1}+K_{2}}\right)-h P_{2}
\end{aligned}
$$

The model itself is made up of two differential equations relating to the population of animals on the properties. The equations (2-3) correspond to the rate of change in animal numbers on both properties and consist of a maximal growth rate $(r)$ multiplied by a logistic term. The migration term is included in both the equations and the harvest term is included in equation (3). The harvest term consist of harvesting rate $(h)$ multiplied by the number of animals $\left(P_{2}\right)$ (see Table 1 for details).

Table 1. Nomenclature for the single species model.

\begin{tabular}{|c|l|}
\hline Notation & Definitions \\
\hline$P_{1}, P_{2}$ & The number of species on property 1 and property 2 respectively. \\
\hline$r$ & $\begin{array}{l}\text { The maximal growth rate for species of property } 1 \text { and property } 2 \text { respectively (growth rate given optimal } \\
\text { conditions) }\left(y r^{-1}\right) .\end{array}$ \\
\hline$K_{1}, K_{2}$ & $\begin{array}{l}\text { The carrying capacity for property } 1 \text { and property } 2 \text { respectively in dse, which is a limit to what the } \\
\text { property could maintain. }\end{array}$ \\
\hline$h$ & The specific harvest rate for species on property $2\left(y r^{-1}\right)$. \\
\hline$\alpha$ & Migration coefficient $\left(y r^{-1}\right)$. \\
\hline$T_{\text {Max }}$ & The maximum revenue gained from the tourism on isolated population by fence $P_{1}$. \\
\hline$H_{\text {Max }}$ & The maximum revenue gained from the hunting on isolated population by fence $P_{2}$. \\
\hline Price $_{2}$ & The price of one hunted animal from population $P_{2} \cdot$ \\
\hline
\end{tabular}

The model simulations indicate that when the fence is up, the maximum revenue gained from tourism $\left(T_{\text {Max }}\right)$ on property 1 , is the same as the maximum revenue gained from the hunting $\left(H_{M a x}\right)$ on property 2. The profit functions for property 1 and property 2 respectively are given by:

$$
\begin{aligned}
& R_{1}=T_{\text {Max }} g\left(P_{1}\right) \\
& R_{2}=\text { Price }_{P_{2}} \times h \times P_{2}
\end{aligned}
$$

The profit on property 1 is calculated by multiplying the maximum revenue gained from tourism $\left(T_{\text {Max }}\right)$ by the quadratic function $g\left(P_{1}\right)$, given in equation (8). The quadratic function implies that no revenue occur on property 1 until the number of animals on property 1 reached a minimum value of the carrying capacity of property 1 . The profit on property 2 is calculated by multiplying the price of one hunted animal by the off-take $\left(\right.$ Price $\left._{P_{2}} \times h \times P_{2}\right)$.

When the fence is up, the results for this case is well known. However, this implies that the revenue from nonconsumptive tourism on property 1 is maximized when the populations are kept as large as possible (i.e. at the carrying capacity), where $P_{1}^{*}=K_{1}$. Substituting $P_{1}^{*}$ in Equation 4 gives the optimal profit $R_{1}$. Furthermore, this is also implies that offtake for hunting on property 2 is maximized when the population density is equal to half of the carrying capacity where $P_{2}^{*}=K_{2} / 2$, so that the optimal harvesting rate is $h^{*}=r_{2} / 2$. Substituting $h^{*} \& P_{2}^{*}$ in Equation 5 gives the optimal profit $R_{2}$.

Therefore, we investigate two cases:

- Case1: Using a standard procedure for maximizing harvest on the property 2, the first case, we find $P_{2}, h$ that maximize the following combined objective function for property 2 : 
Mohammed et al., Understanding the impact of removing a fence between two game ranches with different management objectives

$$
\begin{gathered}
\underset{h, P_{2}}{\operatorname{Max}} R_{2}=\text { Price }_{P_{2}} \times h \times P_{2} \\
\text { s.t. } \\
r P_{1}\left(1-\frac{P_{1}}{K_{1}}\right)-\alpha\left(\frac{K_{2} P_{1}-K_{1} P_{2}}{K_{1}+K_{2}}\right)=0 \\
r P_{2}\left(1-\frac{P_{2}}{K_{2}}\right)+\alpha\left(\frac{K_{2} P_{1}-K_{1} P_{2}}{K_{1}+K_{2}}\right)-h P_{2}=0, \\
P_{1} \geq 0 \\
P_{2} \geq 0 \\
h \geq 0
\end{gathered}
$$

- In the second case, we find $P_{1}, P_{2}, h$ that maximize the following combined objective function for both properties to provide an equitable distribution of profits for both properties:

$$
\begin{gathered}
\underset{P_{1}, P_{2}, h}{\operatorname{Max}} R=T_{\text {Max }} g\left(P_{1}\right)+\text { Price }_{P_{2}} \times h \times P_{2} \\
\text { s.t. } \\
r P_{1}\left(1-\frac{P_{1}}{K_{1}}\right)-\alpha\left(\frac{K_{2} P_{1}-K_{1} P_{2}}{K_{1}+K_{2}}\right)=0, \\
r P_{2}\left(1-\frac{P_{2}}{K_{2}}\right)+\alpha\left(\frac{K_{2} P_{1}-K_{1} P_{2}}{K_{1}+K_{2}}\right)-h P_{2}=0, \\
P_{1} \geq 0 \\
P_{2} \geq 0 \\
h \geq 0
\end{gathered}
$$

\section{NUMERICAL EXAMPLE}

To illustrate the model, a numerical example is provided. We consider one species, freely moving between two adjacent properties with no fence between. The parameter values have been estimated from the literature, and don't necessarily relate to any specific species. We assume the properties are identical for all practical puroses, and that the population is equally distributed at time zero. We assume also that the population is at a stable equilibrium, and that the changes are due soley to migration and harvest.

Table 2. Parameter values used in this study.

\begin{tabular}{cl}
\hline Notation & Value \\
\hline$P_{1}, P_{2}$ & State Variable \\
$h$ & Control Variable \\
$K_{1}, K_{2}$ & 150,150 \\
$r$ & 0.1 \\
$\alpha$ & 0.15 \\
\hline
\end{tabular}

The minimum value of carrying capacity of property 1 before the revenue occurs is assumed (50 animal units), thus:

$$
R_{1}=T_{\text {Max }} g\left(P_{1}\right)=T_{\text {Max }}\left\{\begin{array}{c}
\left(-\frac{1}{10000}\left(P_{1}-50\right)^{2}+\frac{1}{50}\left(P_{1}-50\right)\right), \\
0 \quad \text {,Otherwise }
\end{array}\right.
$$


Mohammed et al., Understanding the impact of removing a fence between two game ranches with different management objectives

\section{RESULTS AND DISCUSSION}

When the fence is in place, the resulting population distribution has been well studied and publicized. This study concentrates on the effect of removing the fence. This is by implications, a cooperative arrangement. This investigation is designed to provide information to landowners if the fence is removed under this scenario (see eqation 6).

Landholder 1 has no control over his population when the fence is removed. Once harvesting is implemented on property 2, property 1 starts to lose animals through the migration. This gives insight about the effect of the migration on the profits of two landholders. Table 3 shows the decrease in individuals on property 1, and consequent decrease in property 1 revenue, while property 2 revenue increases.

Table 3. The results for optimizing the amount the system of combine properties (1\&2) to produce sustainably (case 1).

\begin{tabular}{ll}
\hline The optimal equilibrium population $P_{1}^{*}$ & 78.76 (animal) \\
The optimal equilibrium population $P_{2}^{*}$ & 71.28 (animal) \\
The optimal equilibrium harvest rate $h^{*}$ & 0.104965 (fraction of animal per year) \\
The optimal number of animals harvested $\left(h^{*} P_{2}^{*}\right)$ & 7.48 (animal) \\
\hline
\end{tabular}

In this scenario, the model is able to provide an equitable distribution of return for both landholder $1 \&$ landholder 2 by controlling the harvest rate. The optimal profit for landholder $1(R 1)$ is very close to the optimal profit for landholder 2 as shown in Table 4 and Figure 1 (see equation 7).

Table 4. The results for the fence-removed scenario (case 2), optimizing the amount the system of combine properties (1\&2) to produce sustainably.

\begin{tabular}{ll}
\hline The optimal equilibrium population $P_{1}^{*}$ & 130.672 (animal) \\
The optimal equilibrium population $P_{2}^{*}$ & 127.305 (animal) \\
The optimal equilibrium harvest rate $h^{*}$ & 0.028356 (fraction of animal per year) \\
The optimal number of animals harvested $\left(h^{*} P_{2}^{*}\right)$ & 3.61 (animal)
\end{tabular}

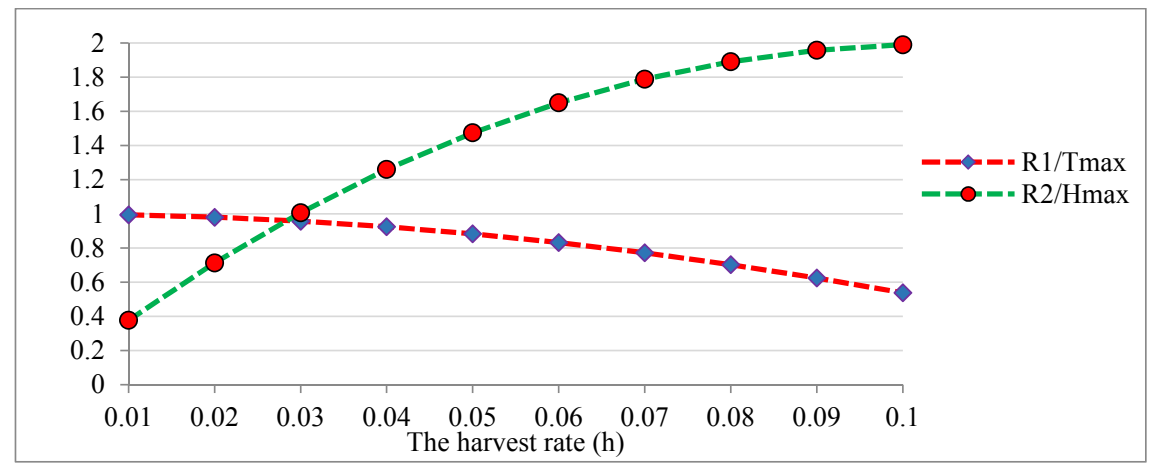

Figure 1. The relationship between the harvest rate (h) and the ratios (R1/Tmax \& R2/Hmax).

Figure 1 shows that once hunting starts on property 2, the profit of landholder 1 decreases. This is because property 2 has a lower density of animals, which means more migration to property 2 . However, to provide an equitable distribution of returns for both landholders the harvest rate must be considered. The intersection point of both ratios (R1/Tmax \& R2/Hmax) can help to find the right harvest rate (in this case $\left.h^{*}=0.028356\right)$ so that the profits of both landholders are equal. 
Mohammed et al., Understanding the impact of removing a fence between two game ranches with different management objectives

\section{CONCLUSION}

The model investigates the optimization of wildlife strategies for property owners in a collaborative enterprise with different aims, namely, a tourism enterprise objective and a hunting enterprise objective.

The study indicates decreasing returns from non-consumptive tourism enterprise on property 1 when the fence is removed and property 2 is running an optimal enterprise. This decrease is because the animals migrate from property 1 to the neighbouring property 2 which has a lower density of animals due to the hunting. By considering a cooperative practice between both landowners, the intersection point of both ratios (R1/Tmax \& $\mathrm{R} 2 / \mathrm{Hmax}$ ) can help to find the harvest rate that leads to the equitable distribution of returns for both landowners.

\section{REFERENCES}

Behr, J., and J. A. Groenewald. "Commercial Game Utilization on South African Farms." Agrekon 29, no. 1 (1990): 55-58.

Child, B. "Private Conservation in Southern Africa: Practice and Emerging Principles. In Evolution and Innovation in Wildlife Conservation in Southern Africa (Eds B. Child, H. Suich \& A. Spencely)." Earthscan, London, UK. (2009): 103-12.

Child, Brian, Jessica Musengezi, Gregory Parent, and Graham Child. "The Economics and Institutional Economics of Wildlife on Private Land in Africa." Pastoralism: Research, Policy and Practice 2, no. 1 (2012): 1-32.

Clark, Colin Whitcomb. Mathematical Bioeconomics : The Mathematics of Conservation. 3rd ed. ed. Hoboken, N.J.: Wiley, 2010.

E. J. Milner-Gulland, John M. Fryxell, and Anthony R. E. Sinclair. "Animal Migration: A Synthesis." The Journal of Wildlife Management 79, no. 3 (2011): 520-21.

Fretwell, Stephen, and Henry Lucas. "On Territorial Behavior and Other Factors Influencing Habitat Distribution in Birds." An international journal on the mathematical and philosophical foundations of biological and biomedical science 19, no. 1 (1970): 16-36.

Leimgruber, Peter, William J. McShea, Christopher J. Brookes, Lhamsuren Bolor-Erdene, Chris Wemmer, and Chris Larson. "Spatial Patterns in Relative Primary Productivity and Gazelle Migration in the Eastern Steppes of Mongolia." Biological Conservation 102, no. 2 (2001): 205-12.

Lindsey, P. "An Analysis of Game Meat Production and Wildlife-Based Land Uses on Freehold Land in Namibia: Links with Food Security." TRAFFIC East/Southern Africa, Harare, Zimbabwe. (2011): 22-63.

Lindsey, P. A., C. P. Havemann, R. M. Lines, A. E. Price, T. A. Retief, T. Rhebergen, C. Van der Waal, and S. S. Romañach. "Benefits of Wildlife-Based Land Uses on Private Lands in Namibia and Limitations Affecting Their Development." 47, no. 1 (2013): 41-53.

Lindsey, Peter A., R. Alexander, M. G. L. Mills, S. Romañach, and R. Woodroffe. "Wildlife Viewing Preferences of Visitors to Protected Areas in South Africa: Implications for the Role of Ecotourism in Conservation." Journal of Ecotourism 6, no. 1 (2007): 19-33.

Mwakiwa, E., W. de Boer, J. Hearne, R. Slotow, F. van Langevelde, M. Peel, C. Grant, Y. Pretorius, J. Stigter, A. Skidmore, I. Heitkonig, H. de Knegt, E. Kohi, N. Knox, and H. Prins. "Optimization of Wildlife Management in a Large Game Reserve through Waterpoints Manipulation: A Bio-Economic Analysis." (2013).

Nogueira, Selene, and Sérgio Nogueira-Filho. "Wildlife Farming: An Alternative to Unsustainable Hunting and Deforestation in Neotropical Forests?" Biodiversity \& Conservation 20, no. 7 (2011): 1385-97.

Prins, Herbert H. T. editor, Jan Geu Grootenhuis, and Thomas T. Dolan. Wildlife Conservation by Sustainable Use. Edited by Jan Geu editor Grootenhuis, Thomas T. editor Dolan and SpringerLink, Conservation Biology Series, Vol. 12: Springer Netherlands : Imprint: Springer, 2000.

Roth, Harald H. editor, and Günter Merz. Wildlife Resources a Global Account of Economic Use. Edited by Günter editor Merz and SpringerLink: Springer Berlin Heidelberg : Imprint: Springer, 1997.

Taubes, Clifford. Modeling Differential Equations in Biology. Upper Saddle River, N.J.: Prentice Hall, 2001. 